Neurol Clin. 2012 November ; 30(4): 1167-1191. doi:10.1016/j.ncl.2012.08.011.

\title{
Circadian Rhythm Sleep Disorders
}

\author{
Lirong Zhu, MD, PhDa and Phyllis C. Zee, MD, PhDa, ${ }^{*}$ \\ Lirong Zhu: lirong-zhu@fsm.northwestern.edu \\ aDepartment of Neurology, Northwestern University, 710 North Lake Shore Drive, 11th Floor, \\ Chicago, IL 60611, USA
}

\begin{abstract}
There have been remarkable advances in our understanding of the molecular, cellular and physiological mechanisms underlying the regulation of circadian rhythms, as well as the impact of circadian dysfunction on health and disease. This information has transformed our understanding of the effect of circadian rhythm sleep disorders (CRSD) on health, performance and safety. CRSDs are caused by alterations of the central circadian time-keeping system, or a misalignment of the endogenous circadian rhythm and the external environment. In this section, we provide a review of circadian biology and discuss the pathophysiology, clinical features, diagnosis, and treatment of the most commonly encountered CRSDs in clinical practice.
\end{abstract}

\section{Keywords}

Circadian rhythm; Light; Melatonin; Sleep Phase; Shift work; Jet lag

\section{Overview of Human Circadian Biology}

Circadian rhythms are ubiquitous in all living organisms and nearly all physiological functions, most notably sleep and wake cycles, exhibit circadian rhythmicity. Circadian rhythms are endogenous and persist in the absence of environmental time cues. The suprachiasmatic nucleus ( $\mathrm{SCN}$ ), a paired structure in the anterior hypothalamus ${ }^{1}$ is the site of a master circadian clock. It is composed of a network of $\sim 20,000$ neurons in human and displays a self-sustained circadian (near 24 hour) rhythm in neuronal firing ${ }^{2-5}$. The SCN plays a pivotal role in coordinating circadian rhythmicity by communicating timing information to oscillators in tissues elsewhere in the brain, and almost all the peripheral tissues and organs ${ }^{6-9}$. As a result, in virtually every physiological and behavioral parameter follows the roughly 24-hour (circadian) rhythms, among them the sleep/wake cycle is the most apparent. Either disruption of the endogenous circadian control mechanism or misalignment between internal circadian rhythms with the 24-hour outside environment would result in circadian rhythm disorders with adverse consequences in sleep and many other aspects of human health, including metabolism dysfunction, cognitive impairment, cardiovascular abnormalities, gastrointestinal and genitourinary dysfunctions ${ }^{10,11}$.

\footnotetext{
(c) 2012 Elsevier Inc. All rights reserved.

"Correspondence should be addressed to: Phyllis C. Zee, MD, PhD, Professor of Neurology, Director Sleep Disorders Center, Northwestern University, 710 N. Lake Shore Drive, Chicago, IL 60611, p-zee@ northwestern.edu.

Publisher's Disclaimer: This is a PDF file of an unedited manuscript that has been accepted for publication. As a service to our customers we are providing this early version of the manuscript. The manuscript will undergo copyediting, typesetting, and review of the resulting proof before it is published in its final citable form. Please note that during the production process errors may be discovered which could affect the content, and all legal disclaimers that apply to the journal pertain.
} 
In humans, the endogenous period of the circadian oscillation is slightly longer than 24 hours ${ }^{12}$. Evidence from animal and human studies demonstrates a genetic basis for the generation of circadian rhythms. A molecular machinery (transcription-translation feedback loops) drives circadian rhythms in both SCN and peripheral cells at transcription, translation, and posttranslational levels ${ }^{13,14}$. The CLOCK-BMAL1 heterodimer is a transcriptional activator which binds to the E-box located upstream of the Period (Per), Cryptochrome (Cry), Retinoid-related Orphan Receptor (Ror) and Rev Erb genes ${ }^{15,16}$. After transcription and translation, these proteins accumulate in the cytoplasm. In the cytoplasm, PER is phosphorylated by several isoforms of casein kinase I (CKI), including CKI delta and CKI epsilon, which regulates the stability of PER and subcellular localization ${ }^{17-19}$. After PER reaches a critical level, it permits dimerisation with CRY and nuclear translocation. In the nuclear, CRY suppresses CLOCK-BMAL1 induced transcription of Per, Cry, Ror and $R e v-E r b$ in a negative feedback loop (see review ${ }^{20}$ ). PER2 activates Bmal transcription ${ }^{21}$. ROR and REV-ERB translocate to the nucleus independently and bind to the Bmal promoter. ROR activates $B m a l$ transcription, while REV-ERB inhibits it, which generate a rhythmic level of BMAL1 ${ }^{16,22}$. Most clock component messenger RNAs and protein has a 24-h oscillating rhythm except for fCLOCK, CKI delta and CKI epsilon (see review ${ }^{23}$ ).

The endogenous circadian rhythm is synchronized or entrained to the 24 hour rhythm of the external environments daily by synchronizing agents, including light, physical activity, social behaviors and melatonin. Among them, the light is the most influential entraining agent ${ }^{24}$. The phase-shifting effect of light on the circadian rhythm is dependent on the intensity, duration and time of light exposure (Figure 1). A phase response curve (PRC) is a graph of the amount of the phase shift plotted against the circadian time of administration of the stimulus. Exposure of light in the biological evening or early night will delay the circadian pacemaker causing the circadian cycle to shift late relative to clock time. In contrast, exposure of light in the biological morning will advance the circadian pacemaker resulting in the circadian cycle to shift early relative to clock time ${ }^{24}$. The melanopsin containing retinal ganglion cell is the primary circadian photoreceptor and most sensitive to blue light ${ }^{25,26}$. The photic information reaches the SCN through a direct pathway - the retinohypothalamic tract ${ }^{27}$, and an indirect pathway -from the optic tract to the intergeniculate leaflet and then to the SCN via the geniculohypothalamic $\operatorname{tract}^{28}$.

The SCN signals the pineal gland via the superior cervical ganglion to inhibit the production of melatonin, an important entraining agent produced by the pineal gland ${ }^{29}$. In darkness, this inhibition effect is removed and the release of melatonin feeds back to inhibit the firing rate of SCN neurons permitting the sleep drive $\mathrm{e}^{30,31}$. Similar to light, timed administration of melatonin can phase-shift the circadian clock according its phase-response curve (PRC) that is nearly opposite in phase with the PRCs for light exposure ${ }^{32}$ (Figure 1). Exogenous melatonin advances the circadian rhythm when administered in the biological early evening before the nadir of core body temperature, but delays the circadian rhythm when administered in the biological morning after the nadir of core body temperature ${ }^{33}$. Physical activity has also been shown to have phase shifting effects ${ }^{34,35}$.

The sleep-wake cycle is regulated by a complex interaction between the homeostatic process (a drive for sleep which builds up during wakefulness and declines during sleep) and circadian process (a sleep-wake independent 24-hour oscillatory rhythm that modulates sleep propensity). The circadian drive for sleep is the highest at the end of biological night and lowest at the end of biological day. In the entrained situation, when homeostatic drive for sleep dissipates with sleep, the circadian drive for sleep increases in a compensatory manner to facilitate the consolidation of sleep. Conversely, when homeostatic drive for sleep increases with wakefulness during the biological day, the circadian drive for sleep decreases 
and helps the consolidation of wakefulness ${ }^{36}$. Therefore, proper alignment between the homeostatic and circadian processes is critical for optimal sleep quality and performance.

\section{Introduction of Circadian Rhythm Sleep Disorders (CRSD)}

CRSDs arise from a chronic or recurrent pattern of sleep and wake disturbance that is due to dysfunction of the circadian clock system, or misalignment between the timing of the endogenous circadian rhythm and externally imposed social and work cycles, that result in clinically significant functional impairments ${ }^{37}$. CRSDs can be categorized according to their postulated underlying mechanisms: 1) the endogenous circadian clock itself is altered (delayed sleep phase disorder, advanced sleep phase disorder, irregular sleep wake rhythm, and free-running disorder); 2) the external environment and/or social circumstances are altered relative to the endogenous circadian clock (jet lag and shift work disorder).

The diagnosis of CRSD is based on a detailed history of the patient's sleep and wake pattern, and diagnostic tools, such as a sleep diary and actigraphy. In addition, assessment of the timing of physiological circadian rhythm markers, such as core temperature and melatonin are useful diagnostic tools that can be used to confirm the diagnosis. Actigraphy watches are typically worn on the non-dominant wrist for 7 to 14 days to record patterns of rest/activity cycles. Melatonin rhythm and body temperature rhythm are reliable biological phase markers of the endogenous circadian rhythm and exhibit distinct phase relationships with the sleep-wake rhythm. Regulated by the SCN, and under dim light condition, the pineal gland begins to secrete melatonin (Dim light melatonin onset or DLMO) about 2-2.5 hours before sleep onset. The nadir of the core body temperature rhythm occurs approximately 2 hours before habitual sleep offset ${ }^{38}$.

Because patients with CRSD commonly present with symptoms of insomnia and/or excessive sleepiness, circadian abnormalities should be considered in the differential diagnosis or as a co-morbid condition in all patients with sleep and wake disturbances (Figure 2). Table 1 summarizes the common clinical features and treatment approaches for CRSD. The management of CRSD requires a multimodal approach because biological, behavioral and environmental factors all can contribute to the development and severity of presenting symptoms.

\section{Delayed Sleep Phase Disorder (Delayed Sleep phase syndrome, Delayed Sleep Phase Type)}

Delayed sleep phase disorder (DSPD) is a sleep disorder in which there is a stable delay of the major sleep episode relative to the required sleep/wake clock time. This delayed pattern leads to chronic symptoms of insomnia and excessive sleepiness associated with impairment in daytime functioning.

\section{Epidemiology and Risk Factors}

DSPD is the most common CRSD with an estimated prevalence of $0.17 \%$ in the general population ${ }^{39}$ and $7-16 \%$ among adolescents ${ }^{40,41}$. It has been estimated that $5-10 \%$ of chronic insomnia patients in sleep clinics have DSPD ${ }^{42}$. Several studies indicate a genetic predisposition for DSPD. For example, a length polymorphism in $\mathrm{h} P E R 3$ is correlated significantly with extreme diurnal preference ${ }^{43-45}$. Association of circadian chronotypes of diurnal preference have been reported with polymorphisms in $\mathrm{h} C L O C K^{46}, \mathrm{hPER} 1^{47}$, and $\mathrm{h} P E R 2^{48}$, and a missense variation of $\mathrm{S} 408 \mathrm{~N}$ in hCKIepsilon ${ }^{49}$ was found to play a protective role in DSPD and free-running disorder. A polymorphism of Arylalkylamine $\mathrm{N}$ - 
acetyltransferase ${ }^{50}$ and the frequency of HLA-DR1 were found to be significantly higher in the patients with DSPD when compared with healthy controls ${ }^{51}$.

\section{Pathophysiology}

In addition to genetic vulnerability, physiological, behavioral and environmental factors likely play important roles in the development of DSPD. Several mechanisms have been proposed: 1) An unusually long endogenous circadian period ${ }^{52}$ may alter the relationship between sleep onset or offset with the timing of other endogenous circadian rhythms. For example, patients with DSPD have been shown to have a greater interval between sleep offset and nadir of core body temperature ${ }^{53,54}$;2) Alteration in entrainment mechanisms. DSPD patients have been shown to have a hypersensitivity of melatonin suppression to light at night ${ }^{55}$. There is also evidence that the advance portion of the PRC to light in DSPD patients may be smaller than usual ${ }^{56}$; 3) Altered homeostatic process indicated by the alterations in slow-wave activity ${ }^{54}$ and sleep propensity in response to sleep deprivation $^{57,58}$; 4) Behavioral factors precipitate and perpetuate DSPD. For example, the delayed sleep and wake times of patients with DSPD is often associated with less light exposure in the phase advance portion of the PRC curve (morning) and more light exposure in the phase delay portion of the PRC curve (evening).

\section{Clinical Features and Diagnosis}

With work, school or social constraints, patients with DSPD typically present with symptoms of chronic difficulty falling asleep before 2 am- 6 am and inability to wake up in the morning. When allowed to choose their natural preferred schedules, their sleep is usually of normal quality and duration for age. When attempting to comply with their school and occupational obligations, sleep duration is curtailed, resulting in chronic partial sleep deprivation and associated excessive daytime sleepiness and impairment of daily functioning.

The diagnosis of DSPD is largely based on obtaining a detailed sleep history of a sleep and wake pattern that is chronically and stably delayed. A sleep dairy and/or wrist actigraphy (Figure 3A) for at least 7 consecutive days (longer if possible) is indicated to establish the habitually delayed sleep/wake pattern. In addition, biological markers of circadian timing can be useful and are desirable if available. Dim light melatonin onset (DLMO) (Figure 3B) and nadir of core body temperature have been used in clinical practice and demonstrate as expected a delayed phase. Nocturnal polysomnography is not indicated unless there is suspicion of concomitant disorders such as sleep disordered and other causes of insomnia or daytime sleepiness ${ }^{59}$. DSPD is strongly associated with anxiety and depression, so mood disorders screening should be considered in all patients ${ }^{60,61}$.

\section{Treatment}

The management of DSPD requires a combined approach using behavioral techniques, manipulation of light/dark exposure, and in some patients, pharmacological agents. The treatment of DSPD includes adherence to good sleep habits, regular sleep and wake times, chronotherapy, timed bright light therapy and pharmacotherapy. Chronotherapy is a treatment in which the sleep and wake times are progressively delayed by about 3 hours every 2 days until a final earlier bedtime schedule is achieved and maintained ${ }^{56}$. Although effective, adherence is generally poor due to the requirement for the strict scheduling of social, school and work activities and very careful control of the time of light exposure. Despite its challenges, chronotherapy is particularly useful in treating children and adolescents. 
Timed bright light therapy is one of the most commonly used treatments for DSPD. Exposure to light in the biological evening or early night phase delays circadian rhythms, while exposure to light in the morning results in phase advances ${ }^{24}$. Therefore, bright light of 2,000 to 2,500 lux for 2 hours in the biological morning combined with avoidance of bright light exposure in the biological night can effectively achieve earlier sleep and wake times in DSPD patients ${ }^{62}$. Exposure to bright light between 7-9 am is usually effective for most DSPD patients. However, for patients who are more severely delayed (whose endogenous sleep time is after $3 \mathrm{AM}$ and wake time after $9 \mathrm{am}$, the time of morning light exposure should be given later in the morning (shortly after awakening) to avoid light exposure before the nadir of core body temperature which could further delay circadian rhythms. Compliance with light therapy can be challenging due to the inability of patients to awaken in the morning for light exposure and the need to restructure their social and professional activities around the light regimen. Light therapy in the morning should be accompanied by avoidance of bright light in the evening by using sunglasses or decreasing ambient light intensity.

Due to some of the practical limitations of chronotherapy and timed bright light therapy, the benefit of taking melatonin in the evening has been investigated. The effectiveness of melatonin administration in the evening in the treatment of DSPD has been demonstrated in a number of studies ${ }^{63-67}$. Appropriately timed melatonin (in the early evening) has been shown to decrease sleep latency, increase sleep duration and improve function in DSPD patients 59,65 . One small placebo controlled study in DSPD patients showed that administration of melatonin 0.3 or $3 \mathrm{mg}$ about 6 hours prior to their sleep time, resulted in the largest phase advances of sleep and wake times ${ }^{64}$. Although melatonin is indicated as a treatment for DSPD, large randomized placebo-controlled studies are still needed to establish a standard clinical approach for its use.

In addition to light and melatonin, treatment of DSPD should also include proper sleep hygiene, such as adherence to regular sleep-wake times and structured social and physical activity schedules, and address other factors, such as comorbid psychopathology and other sleep disorders.

\section{Adavnced Sleep Phase Disorder (Advanced Sleep Phase Syndrome, Advanced Sleep Phase Type)}

Advanced Sleep Phase Disorder (ASPD) is a sleep disorder in which there is a stable advance of the major sleep period, characterized by habitual and involuntary sleep onset and wake-up times that are several hours earlier than the desired or conventional clock time.

\section{Epidemiology and Risk Factors}

ASPD is more common among middle and older adults. The estimated prevalence of ASPD is about $1 \%$ in middle-age adults ${ }^{39}$. A genetic basis has been clearly demonstrated in familial ASPD. Missense mutations located in two different genes have been reported to cosegregate with the ASPD phenotype in families with ASPD: S662G located within the casein kinase I (CKI) epsilon binding region in $\mathrm{h} P E R 2$ and T44A in CKIdelta $^{68,69}$. The S662G mutation was found to result in hypophosphorylation of PER2 by CKIepsilon ${ }^{68}$, which shortens circadian period.

\section{Pathophysiology}

In addition to the genetic factors in familial ASPD, a shortened endogenous circadian period has been postulated to be involved in sporadic cases ${ }^{70}$. Other proposed mechanisms include alterations of entrainment mechanisms, such as increased retinal response to light in the 
morning ${ }^{71}$, or increased early morning light exposure, both of which can perpetuate the advanced circadian phase.

\section{Clinical Features and Diagnosis}

Patients with ASPD typically present with complaints of sleepiness in the late afternoon or early evening and difficulty maintaining asleep in the early morning hours. Most report sleep onset between 6 pm-9 pm and wake time of 2 am-5 am. Even when sleep time is voluntarily delayed due to social and occupational obligations, patients continue to wake up earlier than desired, resulting in chronic partial sleep deficiency.

The diagnosis of ASPD largely relies on a detailed sleep history of a stable advance in sleep and wake times. When allowed to sleep at their advanced endogenous sleep time, sleep quality and duration are normal for age. A sleep dairy and/or wrist actigraphy (Figure 4A) for at least 7 consecutive days is recommended to establish the habitual advanced sleep/ wake pattern. Measurement of DLMO is desirable if available and can help confirm the advanced circadian rhythm (Figure 4B). Nocturnal polysomnography is not indicated, except when the history suggests the presence of other sleep disorders, such as sleep apnea (common in older adults).

\section{Treatment}

A combined approach with timed bright light exposure for 2 hours in the evening, planned sleep and wake scheduling and adherence to good sleep hygiene is recommended by the AASM Practice Parameters ${ }^{59}$. Bright light exposure in the evening, typically between 7-9 $\mathrm{pm}$, has been shown to delay the phase of circadian rhythms and improve sleep efficiency ${ }^{72,73}$. Melatonin can theoretically delay circadian rhythms if taken in the early biological morning, but clinical evidence of its efficacy or safety for the treatment of ASPD is lacking. While hypnotic agents are can be useful for the management of sleep maintenance symptoms associated with ASPD, they are not approved by the FDA for the treatment of ASPD.

\section{Non- 24 Hour Sleep-Wake Disorder (Free-Running Disorder, Nonentrained Type, Hypernychthermal Syndrome)}

Non-24 Hour Sleep Wake Disorder (N24HSWD) is characterized by a chronic or recurring pattern of sleep and wake times that are not stably entrained to the 24-hour environmental cycle. There is typically a predicable drift over weeks (usually to later and later times) of sleep onset and wake times.

\section{Epidemiology, Risk Factors and Pathophysiology}

N24HSWD affects approximately $50 \%$ of blind people and is thought to be rare in sighted persons $^{74}$. Sighted patients with N24HSWD are generally evening chronotypes, or may have a history of DSPD. The largest case series of N24HSWD in sighted subjects reported 57 cases identified over a 10 -year period ${ }^{75}$. The etiology of N24HSWD in the blind is the absence or near absence of light perception. The mechanism (s) responsible in sighted individuals is less clear. The primary risk factor in sighted persons appears to be a long circadian period that is beyond the range of entrainment to a 24 hours cycle $^{78}$. Other mechanisms include: 1) decreased response of the circadian clock to light, 2) alteration and reduction of environmental or social cues because of psychiatric illness induced social withdrawal $^{79}, 3$ ) mutation in the Casein Kinase I Epsilon (CK1 1 ) gene ${ }^{49}$. Interestingly, N24HSWD has been reported in sighted individuals following traumatic brain injury ${ }^{76,77}$, but the mechanism is poorly understood. 


\section{Clinical Features and Diagnosis}

Patients with N24HSWD typically complain of insomnia, difficulty waking up in the morning, excessive daytime sleepiness and inability to meet their social and occupational obligations. Since the timing of the sleep-wake cycle is progressively changing (usually to later and later times), there is a history of both symptomatic and asymptomatic episodes. At times when the endogenous circadian rhythm is in phase with the conventional sleep and wake time, their sleep is usually normal, whereas when the nonentrained circadian pacemaker is out of phase with the conventional sleep and wake schedules, they have symptoms of insomnia and excessive sleepiness.

The diagnosis is established primarily by a detailed sleep history and a sleep diary with or without concurrent actigraphy for at least 14 days (Figure 5). Actigraphy is particularly useful because depending on the length of the endogenous circadian period, a clear nonentrained pattern may not be evident for several weeks. Most sighted persons with N24HSWD have an evening chronotype, and may exhibit episodes of delayed sleep phase. But unlike patients with DSPD, patients with N24HSWD cannot maintain a stable delayed sleep-wake pattern. It is important to make the distinction between DSPD and N24HSWD because treatment of DSPD with chronotherapy may precipitate the development of a N24HSWD ${ }^{80}$.

\section{Treatment}

The goal of treatment of N24HSWD is to improve sleep quality and daytime function by establishing stable entrainment of the sleep-wake pattern to the 24 hour external cycle. In the blind, the primary approach is a combination of good sleep hygiene, structured social, school and work schedules, and low dose melatonin $(0.5 \mathrm{mg})$ one hour before their preferred sleep time ${ }^{81-83}$. Many blind patients, whose circadian period is close to 24 hours are able to can maintain entrainment with even lower nightly doses of 20-300 $\mu \mathrm{g}$.

A practical approach is to start with a higher dose of melatonin $(3-5 \mathrm{mg})$ for the first month 1-2 hours before bedtime. Once entrainment is established, a lower dose of $0.5 \mathrm{mg}$ can be used for maintenance therapy. For sighted patients, the addition of bright light eposure in the morning, shortly after awakening is a very useful option. B12 has also been proposed as a treatment ${ }^{84}$, but the evidence from case reports is inconclusive and is not a recommended treatment by the AASM Practice Parameters ${ }^{59}$.

\section{Irregular Sleep-Wake Rhythm Disorder (Irregular Sleep-Wake Type, Irregular Sleep-Wake Disorder)}

Irregular sleep-wake rhythm Disorder (ISWRD) is characterized by temporal disorganization of the circadian sleep-wake rhythm, resulting in multiple short sleep and wake bouts occurring throughout the 24 hour cycle.

\section{Epidemiology, Risk Factors and Pathophysiology}

The exact prevalence of the ISWR in the general population is unknown, but is commonly reported in institutionalized residents, particularly in those with dementia, children with mental retardation and individuals with traumatic brain injury ${ }^{85-89}$. The most accepted etiology is a dysfunction of the central circadian clock system due to neurodegeneration or injury. In addition, decreased exposure to synchronizing agents, such as light and structured activities during the day in institutionalized patients can decrease the strength of an already weakened circadian oscillation and thus exacerbate the temporal disorganization of sleep- 
wake behaviors ${ }^{90}$. Other external factors such as nighttime noise and adverse effect of medications can further disrupt sleep and increase daytime naps.

\section{Clinical Presentation and Diagnosis}

Patients with ISWR or their caregivers typically report chronic symptoms of difficulty maintaining sleep during the night and excessive daytime sleepiness. The diagnosis is made primarily by a careful history of a minimum of 3 irregular sleep-wake bouts occurring in a 24-hour cycle recorded for at least 7 days, preferably longer by sleep diary and/or actigraphy. The sleep and wake episodes occur in short intervals of 1-4 hours throughout the 24 hours. Total sleep time per day may be normal for age. Poor sleep hygiene, voluntary irregular sleep-wake schedules, other medical or mental disorders with similar clinical presentation must be considered in the differential diagnosis.

\section{Treatment}

The goal of the treatment of ISWR patients is to consolidate sleep during the night and maintain wakefulness during the daytime. A multimodal approach consisting of structured activities during the day, increasing daytime light exposure, and addressing nighttime noise and nocturia are basic for all patients with ISWRD ${ }^{59}$. Exposure to 3000-5000 lux bright light for 2 hours in the morning for 4 weeks improved daytime alertness, decreased napping, consolidated nighttime sleep and reduced nocturnal agitation ${ }^{91}$.

Several randomized controlled studies showed that the combination of increasing daytime light exposure and social activity, evening melatonin administration, structured physical activity, and minimizing nighttime light and noise exposure are helpful for improving the robustness of rest/activity rhythms and reducing the nighttime awakenings in institutionalized residents with disrupted sleep/wake patterns ${ }^{92-95}$. However, the evidence for the efficacy of melatonin as a single treatment has been best inconsistent in older adults and in patients with dementia ${ }^{95,96}$, and thus $\mathrm{n}$ recommended. Treatment with melatonin alone was found to be associated $\mathrm{w}$ withdrawn behavior and mood disturbance in one study ${ }^{95}$. However, melatonin may more effective in children with ISWR and mental retardation. Melatonin 3 administered in the evening increased nighttime sleep duration, improved sle efficiency, and reduced daytime naps in these children ${ }^{97}$.

\section{Shift Work Disorder (SWD)}

SWD occurs when work hours are scheduled during the habitual sleep ti resulting in chronic complaints of insomnia and excessive daytime sleepiness, resulti impairment of function that are temporarily associated with the unconventional wo schedules.

\section{Epidemiology, Risk Factors and Pathophysiology}

Most shift workers do not have SWD. The estimated prevalence of SWD is $\sim 10$ in night and rotating shift workers ${ }^{98}$. Factors that influence the ability to cope with shift work include age, type of work schedule, domestic responsibilities, diurnal preference, commute time, and other sleep disorders (e.g., sleep apnea, narcolepsy) ${ }^{99,100}$. Sleep disturbance is most commonly associated with night or early morning shifts ${ }^{101,102}$.

\section{Clinical Presentation and Diagnosis}

SWD is characterized by symptoms of insomnia and excessive sleepiness when patients sleep or work at an adverse circadian phase relative to their endogenous circadian sleep and wake propensity rhythm. These impairments persist despite optimizing environmental 
conditions for sleep. As a result, most patients, particularly night workers are chronically sleep deprived by 1-4 hours per day ${ }^{101}$. Chronic partial sleep deprivation associated with SWD can result in reduced alertness and performance capacity. Excessive sleepiness usually occurs during the shift (mainly night or early morning) when the circadian propensity for sleep is high. These symptoms may persist on days off or for several days after the last work shift. In addition, the unconventional work schedule often interferes with family time and impaired social relationships.

Other symptoms of SWD include chronic fatigue, malaise, mood disorder, gastrointestinal problems and decreased libido. Risk of alcohol and substance abuse is increased, as is the risk of weight gain, hypertension, cardiovascular disease and breast and endometrial cancer $^{98}$. In addition to the medical co-morbidities, SWD is associated with significant loss of productivity, increased health care utilization and increased risk for personal and public safety.

The diagnosis of SWD is reliant on obtaining a careful sleep and work history that documents the chronic impairments in sleep and functioning occur in relation to the shift work schedule. A sleep diary and/or actigraphy for at least 7 days, but preferably longer are useful tools to determine the relationship between sleep and work ${ }^{59,103}$. Polysomnography is not specifically indicated, but is recommended to evaluate for other co-morbid sleep disorders such as sleep disordered breathing, primary hypersomnias and parasomnias.

\section{Treatment}

The goal of treatment is to improve sleep quality, alertness and performance at work and overall quality of life. Although symptomatic management may be necessary during the course of adaptation to shift work, the ideal approach is to ensure good sleep hygiene and to realign circadian rhythms with the work schedule. Short-acting hypnotic medications can be used to treat associated insomnia, but they are not FDA approved specifically for the treatment of SWD ${ }^{104-109}$. Appropriate alignment of circadian rhythms will improve sleep quality, increase alertness and performance during the shift, and safety (Figure 6). The bulk of the treatment data comes from night shift workers. In night workers, the aim is to induce a delay shift of circadian rhythms, so that alertness is highest during the night (work) and sleep propensity is highest during the late morning and afternoon.

Bright light exposure (continuous or intermittent) 2,500 to 9,500 lux started early of the night shift and terminated approximately 2 hours before the end of the shift (induces a phase delay) and/or wearing dark glasses or blue light blocking glasses to avoid light exposure in the morning after the night shift (avoiding advance shift) facilitate circadian rhythm adaptation ${ }^{110-113}$. The combination bright light exposure at work and avoidance of bright light in the morning is the most effective approach ${ }^{111,113,114}$. However, there is some concerns about the use of dark goggles when driving because of the alerting effect of bright light ${ }^{115}$. Melatonin can potentially induce a delay shift of circadian rhythms when administered in the morning in night workers. Although administration of melatonin before bedtime in night SWD patients has been shown to improve daytime sleep duration ${ }^{116}$, it does not appear to significantly improve alertness. Excessive sleepiness is perhaps the most debilitating problem for many patients with SWD, and can persist despite therapies aimed at improving sleep quality. A short 1-2 hours nap 2-3 hours prior to the shift work, or even relatively short duration (20 minutes) naps at work when possible can decrease sleepiness. Wake-promoting agents such as caffeine and modafinil can also be used to improve alertness and performance during the night shift ${ }^{117-119}$. The combination of naps and intermittent low dose caffeine can further improve alertness during work. Modafinil was approved by FDA for the treatment of excessive sleepiness associated with SWD. Modafinil 
$200 \mathrm{mg}$ taken at the beginning of the shift has been shown to decrease sleepiness, and improve performance on Psychomotor Vigilance Test in patients with SWD. However, it should be noted that residual sleepiness on average remained in the pathologic range $\mathrm{e}^{117}$. Similar effect was observed in one recent study using armodafinil $150 \mathrm{mg}^{120}$. Figure 6 provides an example to illustrate the timely treatment strategy for SWD.

\section{Jet Lag}

Jet lag is characterized by symptoms of difficulty falling asleep or staying asleep, daytime sleepiness, and general malaise due to a temporary misalignment of the internal circadian system with the external physical environment associated with rapid travel across multiple time zones.

\section{Clinical Presentation and Diagnosis}

The diagnosis of jet lag as a disorder is established by a history of symptoms of insomnia and excessive sleepiness that is temporally associated with travel across more than two time zones. The severity of the clinical symptoms depends on the direction of travel and the number of time zone crossed. These symptoms typically subside within a few days or up to one week. However, for frequent travelers, the symptoms and functional impairments can be chronic and severe, prompting them to seek treatment.

In general, it is more difficult to adapt to eastward travel. For eastward travelers, the symptoms at the destination include difficulty falling asleep, excessive daytime sleepiness and decreased daytime performance especially in the morning. For westward travelers, falling asleep is less problematic than maintaining asleep, and early evening sleepiness and decreased performance are especially troublesome. Other common associated symptoms of jet lag include: 1) altered appetite and gastrointestinal function, 2) general malaise 3) fatigue and 4) mood disturbance. Other sleep disorders causing insomnia and/or excessive daytime sleepiness should be considered.

\section{Treatment}

The main treatment goal for jet lag is to accelerate realignment of the endogenous circadian rhythm to the destination's time zone. Circadian adaptation after eastward travel requires advancing the phase of circadian rhythms, whereas westward travel usually requires a phase delay. Phase advancement after eastward travelling is more difficult than phase delay after westward travelling, because the endogenous period of human circadian rhythms is slightly longer than $24 \mathrm{~h}^{121}$.

Circadian synchronizing agents such as timed bright light exposure and exogenous melatonin are recommended. The timing of light exposure depends primarily on the direction of travel and the number of time zones crossed. For example, for eastward flights, one can begin to advance the timing of circadian rhythms by exposure to bright light upon awakening and avoiding light exposure in the evening 122,123 . On the other hand, at the destination, one should avoid bright light too early in the morning, but increase exposure to light in the late morning and afternoon for the first 2-3 days. If flying westward, at the destination, one should stay awake during the daylight hours, increase light exposure in the afternoon and early evening and avoid napping prior to bedtime at the destination.

Although there are no FDA approved pharmacologic therapies for jet lag, results from several studies support the use of melatonin $(0.5 \mathrm{to} 5 \mathrm{mg})$ for alleviating jet lag symptoms with eastward travel ${ }^{124,125}$. One recent placebo controlled study showed that bedtime administration of ramelteon $(1 \mathrm{mg})$, a melatonin receptor agonist, reduced sleep latency in 
subjects travelling eastward across five time zones ${ }^{126}$. However, this effect was only seen under dim light conditions, indicating that light is still the most powerful stimulus for phase re-setting of circadian rhythms.

Other pharmacological agents, including caffeine, armodafinil and short acting hypnotics have been studied for the management symptoms of insomnia and excessive sleepiness associated with jet lag. Wake promoting agents, such as caffeine and armodafinil $150 \mathrm{mg}$ have been shown to have beneficial effects on alertness and fatigue when flying eastward ${ }^{124,127}$. Short acting hypnotics, such as zolpidem $10 \mathrm{mg}$ given for 3 consecutive nights immediately after travel may be effective for improving sleep quality and duration ${ }^{124,128}$. Figure $7 \mathrm{~A}$ and $7 \mathrm{~B}$ provides examples to illustrate the treatment strategy for jet lag for eastward and westward travel.

\section{Summary}

Circadian rhythm sleep disorder is a group of sleep disorders sharing a common underlying etiology of circadian dysfunction that is primarily due to alterations in the central pacemaker and/or its entrainment mechanisms, or to external changes in the physical or social/work environment that lead to circadian misalignment. The most evident manifestation of the circadian disturbance is the prominent changes in sleep and wake function. However, recent evidence clearly shows that circadian dysfunction, not only impairs sleep and wake performance, but also negatively affects the function of multiple organ systems, and increase the risk for cardiovascular, metabolic, cognitive and mood disorders. Given the importance of circadian function in health and disease development, it is important to consider CRSDs in the differential diagnosis of most sleep disorders. Our challenge now is to develop more precise and clinically practical diagnostic tools for the various CRSD', and to conduct large multi-center controlled studies of treatment approaches to establish strong evidence based clinical guidelines. i

\section{Case Study}

A 17-year-old male high school student presents with complaints of difficulty falling asleep at night and excessive daytime sleepiness for about a year. The constant tiredness during the day has significantly affected his school performance and mood. He is often irritable and feels depressed and anxious most of the time. About 3 months ago, his primary care physician prescribed zolpidem $10 \mathrm{mg}$ for insomnia and estacilopram for depression. When he takes zolpidem, he is able to fall asleep on most nights, but still feels very sleepy during the day-especially until noon.

A sleep diary performed showed that his bedtime is about 10pm on school days, but sleep onset was on average between 2-3 am. He would lay in bed, working or watching movies on his laptop. Once asleep, he sleeps soundly. He gets on average about 4 hours of sleep on school nights, and it's a huge struggle to get him to wake up - even at 7:30 am for his 8 am class (which he misses 3 days a week). He often takes a 1 to 2 hour nap after he comes back home after school. On weekends, he stays up until 3 am and wake up without an alarm around $1 \mathrm{pm}$. Remainder of the sleep history is unremarkable.

The most likely diagnosis is delayed sleep phase disorder. The history and sleep diary show a stable delay of his desired sleep period in relation to the conventional sleep time and wakeup time required for school. If allowed to sleep at his natural delayed schedule on weekends, his sleep duration and quality are relatively normal for his age. In fact the long sleep duration on weekends, may indicated "recovery sleep" due the sleep deficiency during the week. Other sleep disorders including narcolepsy or sleep apnea are very unlikely based on 
the history. However, depression and anxiety disorders are common co-morbid conditions and may also require treatment.

Bright light therapy in the morning, avoidance of bright light in the evening-within 3 hours of bedtime and enforcement of a structured sleep and wake schedule, alone or if needed with early evening low dose ( 0.5 to $3 \mathrm{mg}$ ) melatonin ( $8 \mathrm{pm}$-which is approximately 6-7 hours before his sleep time of 2-3 am) and sleep hygiene are recommended treatments for him. Light therapy in the morning (full spectrum or blue enriched) should begin on a weekend or vacation. The initial time to initiate light exposure should be between 9-10 am (shortly after the nadir of the core temperature rhythm), and the timing can be moved earlier by 30 minutes every 2-3 days or an hour per week, until his desired wake time is achieved. To avoid bright light in the evening, he was instructed to use amber colored blue light blocking glasses. If these methods are insufficient or is compliance is poor with light exposure, the addition of Good sleep hygiene, including moderating caffeine intake, exercise, and eliminating his afternoon nap can help him maintain the regularity of his sleep and wake cycles, and also decrease sleep latency by increasing the homeostatic drive for sleep at night.

\section{Suggested Readings and References}

1. Stephan, FK.; Zucker, I. Circadian rhythms in drinking behavior and locomotor activity of rats are eliminated by hypothalamic lesions. Proceedings of the National Academy of Sciences of the United States of America; 1972; p. 1583-1586.

2. Green DJ, Gillette R. Circadian rhythm of firing rate recorded from single cells in the rat suprachiasmatic brain slice. Brain research. 1982; 245:198-200. [PubMed: 6889453]

3. Groos G, Hendriks J. Circadian rhythms in electrical discharge of rat suprachiasmatic neurones recorded in vitro. Neuroscience letters. 1982; 34:283-288. [PubMed: 6298675]

4. Hofman MA, Fliers E, Goudsmit E, Swaab DF. Morphometric analysis of the suprachiasmatic and paraventricular nuclei in the human brain: sex differences and age-dependent changes. Journal of anatomy. 1988; 160:127-143. [PubMed: 3253251]

5. Swaab DF, Fliers E, Partiman TS. The suprachiasmatic nucleus of the human brain in relation to sex, age and senile dementia. Brain research. 1985; 342:37-44. [PubMed: 4041816]

6. McNamara P, Seo SB, Rudic RD, Sehgal A, Chakravarti D, FitzGerald GA. Regulation of CLOCK and MOP4 by nuclear hormone receptors in the vasculature: a humoral mechanism to reset a peripheral clock. Cell. 2001; 105:877-889. [PubMed: 11439184]

7. Storch KF, Lipan O, Leykin I, et al. Extensive and divergent circadian gene expression in liver and heart. Nature. 2002; 417:78-83. [PubMed: 11967526]

8. Yamazaki S, Numano R, Abe M, et al. Resetting central and peripheral circadian oscillators in transgenic rats. Science. 2000; 288:682-685. [PubMed: 10784453]

9. Fukuhara C, Tosini G. Peripheral circadian oscillators and their rhythmic regulation. Frontiers in bioscience: a journal and virtual library. 2003; 8:d642-651. [PubMed: 12700075]

10. Young ME, Bray MS. Potential role for peripheral circadian clock dyssynchrony in the pathogenesis of cardiovascular dysfunction. Sleep medicine. 2007; 8:656-667. [PubMed: 17387040]

11. Klerman EB. Clinical aspects of human circadian rhythms. Journal of biological rhythms. 2005; 20:375-386. [PubMed: 16077156]

12. Czeisler CA, Duffy JF, Shanahan TL, et al. Stability, precision, and near-24-hour period of the human circadian pacemaker. Science. 1999; 284:2177-2181. [PubMed: 10381883]

13. Yagita K, Tamanini F, van Der Horst GT, Okamura H. Molecular mechanisms of the biological clock in cultured fibroblasts. Science. 2001; 292:278-281. [PubMed: 11303101]

14. Dunlap JC. Molecular bases for circadian clocks. Cell. 1999; 96:271-290. [PubMed: 9988221]

15. Gekakis N, Staknis D, Nguyen HB, et al. Role of the CLOCK protein in the mammalian circadian mechanism. Science. 1998; 280:1564-1569. [PubMed: 9616112] 
16. Preitner N, Damiola F, Lopez-Molina L, et al. The orphan nuclear receptor REVERBalpha controls circadian transcription within the positive limb of the mammalian circadian oscillator. Cell. 2002; 110:251-260. [PubMed: 12150932]

17. Eide EJ, Virshup DM. Casein kinase I: another cog in the circadian clockworks. Chronobiology international. 2001; 18:389-398. [PubMed: 11475410]

18. Akashi M, Tsuchiya Y, Yoshino T, Nishida E. Control of intracellular dynamics of mammalian period proteins by casein kinase I epsilon (CKIepsilon) and CKIdelta in cultured cells. Molecular and cellular biology. 2002; 22:1693-1703. [PubMed: 11865049]

19. Vanselow K, Vanselow JT, Westermark PO, et al. Differential effects of PER2 phosphorylation: molecular basis for the human familial advanced sleep phase syndrome (FASPS). Genes \& development. 2006; 20:2660-2672. [PubMed: 16983144]

20. Ko CH, Takahashi JS. Molecular components of the mammalian circadian clock. Human molecular genetics. 2006; 15 Spec No 2:R271-277. [PubMed: 16987893]

21. Shearman LP, Sriram S, Weaver DR, et al. Interacting molecular loops in the mammalian circadian clock. Science. 2000; 288:1013-1019. [PubMed: 10807566]

22. Guillaumond F, Dardente H, Giguere V, Cermakian N. Differential control of Bmal1 circadian transcription by REV-ERB and ROR nuclear receptors. Journal of biological rhythms. 2005; 20:391-403. [PubMed: 16267379]

23. Toh, KL. Annals of the Academy of Medicine. Vol. 37. Singapore: 2008. Basic science review on circadian rhythm biology and circadian sleep disorders; p. 662-668.

24. Czeisler CA, Allan JS, Strogatz SH, et al. Bright light resets the human circadian pacemaker independent of the timing of the sleep-wake cycle. Science. 1986; 233:667-671. [PubMed: 3726555]

25. Freedman MS, Lucas RJ, Soni B, et al. Regulation of mammalian circadian behavior by non-rod, non-cone, ocular photoreceptors. Science. 1999; 284:502-504. [PubMed: 10205061]

26. Ruby NF, Brennan TJ, Xie X, et al. Role of melanopsin in circadian responses to light. Science. 2002; 298:2211-2213. [PubMed: 12481140]

27. Moore RY, Speh JC, Card JP. The retinohypothalamic tract originates from a distinct subset of retinal ganglion cells. The Journal of comparative neurology. 1995; 352:351-366. [PubMed: 7706557]

28. Pickard GE. Bifurcating axons of retinal ganglion cells terminate in the hypothalamic suprachiasmatic nucleus and the intergeniculate leaflet of the thalamus. Neuroscience letters. 1985; 55:211-217. [PubMed: 4000547]

29. Reppert SM, Perlow MJ, Ungerleider LG, et al. Effects of damage to the suprachiasmatic area of the anterior hypothalamus on the daily melatonin and cortisol rhythms in the rhesus monkey. The Journal of neuroscience: the official journal of the Society for Neuroscience. 1981; 1:1414-1425. [PubMed: 7320754]

30. Jin X, von Gall C, Pieschl RL, et al. Targeted disruption of the mouse Mel(1b) melatonin receptor. Molecular and cellular biology. 2003; 23:1054-1060. [PubMed: 12529409]

31. Liu C, Weaver DR, Jin X, et al. Molecular dissection of two distinct actions of melatonin on the suprachiasmatic circadian clock. Neuron. 1997; 19:91-102. [PubMed: 9247266]

32. Lewy AJ, Bauer VK, Ahmed S, et al. The human phase response curve (PRC) to melatonin is about 12 hours out of phase with the PRC to light. Chronobiology international. 1998; 15:71-83. [PubMed: 9493716]

33. Lewy AJ, Ahmed S, Jackson JM, Sack RL. Melatonin shifts human circadian rhythms according to a phase-response curve. Chronobiology international. 1992; 9:380-392. [PubMed: 1394610]

34. Buxton OM, Frank SA, L'Hermite-Baleriaux M, Leproult R, Turek FW, Van Cauter E. Roles of intensity and duration of nocturnal exercise in causing phase delays of human circadian rhythms. The American journal of physiology. 1997; 273:E536-542. [PubMed: 9316443]

35. Van Reeth O, Sturis J, Byrne MM, et al. Nocturnal exercise phase delays circadian rhythms of melatonin and thyrotropin secretion in normal men. The American journal of physiology. 1994; 266:E964-974. [PubMed: 8023928] 
36. Dijk DJ, Czeisler CA. Paradoxical timing of the circadian rhythm of sleep propensity serves to consolidate sleep and wakefulness in humans. Neuroscience letters. 1994; 166:63-68. [PubMed: 8190360]

37. The international classification of sleep disorders: diagnostic and coding manual, ICSD-2. 2nd. Westchester, IL: American Academy of Sleep Medicine; 2005.

38. Benloucif S, Guico MJ, Reid KJ, Wolfe LF, L'Hermite-Baleriaux M, Zee PC. Stability of melatonin and temperature as circadian phase markers and their relation to sleep times in humans. Journal of biological rhythms. 2005; 20:178-188. [PubMed: 15834114]

39. Schrader H, Bovim G, Sand T. The prevalence of delayed and advanced sleep phase syndromes. Journal of sleep research. 1993; 2:51-55. [PubMed: 10607071]

40. Pelayo RPTM, Glovinski P. Prevalence of delayed sleep phase syndrome among adolescents. Sleep Research. 1988; 17:392.

41. Regestein QR, Monk TH. Delayed sleep phase syndrome: a review of its clinical aspects. The American journal of psychiatry. 1995; 152:602-608. [PubMed: 7694911]

42. Weitzman ED, Czeisler CA, Coleman RM, et al. Delayed sleep phase syndrome. A chronobiological disorder with sleep-onset insomnia. Archives of general psychiatry. 1981; 38:737-746. [PubMed: 7247637]

43. Archer SN, Carpen JD, Gibson M, et al. Polymorphism in the PER3 promoter associates with diurnal preference and delayed sleep phase disorder. Sleep. 2010; 33:695-701. [PubMed: 20469812]

44. Pereira DS, Tufik S, Louzada FM, et al. Association of the length polymorphism in the human Per3 gene with the delayed sleep-phase syndrome: does latitude have an influence upon it? Sleep. 2005; 28:29-32. [PubMed: 15700718]

45. Archer SN, Robilliard DL, Skene DJ, et al. A length polymorphism in the circadian clock gene Per3 is linked to delayed sleep phase syndrome and extreme diurnal preference. Sleep. 2003; 26:413-415. [PubMed: 12841365]

46. Katzenberg D, Young T, Finn L, et al. A CLOCK polymorphism associated with human diurnal preference. Sleep. 1998; 21:569-576. [PubMed: 9779516]

47. Carpen JD, von Schantz M, Smits M, Skene DJ, Archer SN. A silent polymorphism in the PER1 gene associates with extreme diurnal preference in humans. Journal of human genetics. 2006; 51:1122-1125. [PubMed: 17051316]

48. Carpen JD, Archer SN, Skene DJ, Smits M, von Schantz M. A single-nucleotide polymorphism in the $5^{\prime}$-untranslated region of the hPER2 gene is associated with diurnal preference. Journal of sleep research. 2005; 14:293-297. [PubMed: 16120104]

49. Takano A, Uchiyama M, Kajimura N, et al. A missense variation in human casein kinase I epsilon gene that induces functional alteration and shows an inverse association with circadian rhythm sleep disorders. Neuropsychopharmacology: official publication of the American College of Neuropsychopharmacology. 2004; 29:1901-1909. [PubMed: 15187983]

50. Hohjoh H, Takasu M, Shishikura K, Takahashi Y, Honda Y, Tokunaga K. Significant association of the arylalkylamine $\mathrm{N}$-acetyltransferase (AA-NAT) gene with delayed sleep phase syndrome. Neurogenetics. 2003; 4:151-153. [PubMed: 12736803]

51. Hohjoh H, Takahashi Y, Hatta Y, et al. Possible association of human leucocyte antigen DR1 with delayed sleep phase syndrome. Psychiatry and clinical neurosciences. 1999; 53:527-529. [PubMed: 10498237]

52. Ozaki N, Iwata T, Itoh A, et al. Body temperature monitoring in subjects with delayed sleep phase syndrome. Neuropsychobiology. 1988; 20:174-177. [PubMed: 3255890]

53. Uchiyama M, Okawa M, Shibui K, et al. Altered phase relation between sleep timing and core body temperature rhythm in delayed sleep phase syndrome and non-24-hour sleep-wake syndrome in humans. Neuroscience letters. 2000; 294:101-104. [PubMed: 11058797]

54. Watanabe T, Kajimura N, Kato M, et al. Sleep and circadian rhythm disturbances in patients with delayed sleep phase syndrome. Sleep. 2003; 26:657-661. [PubMed: 14572116]

55. Aoki H, Ozeki Y, Yamada N. Hypersensitivity of melatonin suppression in response to light in patients with delayed sleep phase syndrome. Chronobiology international. 2001; 18:263-271. [PubMed: 11379666] 
56. Czeisler CA, Richardson GS, Coleman RM, et al. Chronotherapy: resetting the circadian clocks of patients with delayed sleep phase insomnia. Sleep. 1981; 4:1-21. [PubMed: 7232967]

57. Uchiyama M, Okawa M, Shibui K, et al. Poor recovery sleep after sleep deprivation in delayed sleep phase syndrome. Psychiatry and clinical neurosciences. 1999; 53:195-197. [PubMed: 10459687]

58. Uchiyama M, Okawa M, Shibui K, et al. Poor compensatory function for sleep loss as a pathogenic factor in patients with delayed sleep phase syndrome. Sleep. 2000; 23:553-558. [PubMed: 10875562]

59. Morgenthaler TI, Lee-Chiong T, Alessi C, et al. Practice parameters for the clinical evaluation and treatment of circadian rhythm sleep disorders. An American Academy of Sleep Medicine report Sleep. 2007; 30:1445-1459.

60. Schrader H, Bovim G, Sand T. Depression in the delayed sleep phase syndrome. The American journal of psychiatry. 1996; 153:1238. [PubMed: 8780443]

61. Shirayama M, Shirayama Y, Iida H, et al. The psychological aspects of patients with delayed sleep phase syndrome (DSPS). Sleep medicine. 2003; 4:427-433. [PubMed: 14592284]

62. Rosenthal NE, Joseph-Vanderpool JR, Levendosky AA, et al. Phase-shifting effects of bright morning light as treatment for delayed sleep phase syndrome. Sleep. 1990; 13:354-361. [PubMed: 2267478]

63. Dahlitz M, Alvarez B, Vignau J, English J, Arendt J, Parkes JD. Delayed sleep phase syndrome response to melatonin. Lancet. 1991; 337:1121-1124. [PubMed: 1674014]

64. Mundey K, Benloucif S, Harsanyi K, Dubocovich ML, Zee PC. Phase-dependent treatment of delayed sleep phase syndrome with melatonin. Sleep. 2005; 28:1271-1278. [PubMed: 16295212]

65. Nagtegaal JE, Kerkhof GA, Smits MG, Swart AC, Van Der Meer YG. Delayed sleep phase syndrome: A placebo-controlled cross-over study on the effects of melatonin administered five hours before the individual dim light melatonin onset. Journal of sleep research. 1998; 7:135-143. [PubMed: 9682186]

66. Oldani A, Ferini-Strambi L, Zucconi M, Stankov B, Fraschini F, Smirne S. Melatonin and delayed sleep phase syndrome: ambulatory polygraphic evaluation. Neuroreport. 1994; 6:132-134. [PubMed: 7703401]

67. Nagtegaal JE, Laurant MW, Kerkhof GA, Smits MG, van der Meer YG, Coenen AM. Effects of melatonin on the quality of life in patients with delayed sleep phase syndrome. Journal of psychosomatic research. 2000; 48:45-50. [PubMed: 10750629]

68. Toh KL, Jones CR, He Y, et al. An hPer2 phosphorylation site mutation in familial advanced sleep phase syndrome. Science. 2001; 291:1040-1043. [PubMed: 11232563]

69. Xu Y, Padiath QS, Shapiro RE, et al. Functional consequences of a CKIdelta mutation causing familial advanced sleep phase syndrome. Nature. 2005; 434:640-644. [PubMed: 15800623]

70. Jones CR, Campbell SS, Zone SE, et al. Familial advanced sleep-phase syndrome: A short-period circadian rhythm variant in humans. Nature medicine. 1999; 5:1062-1065.

71. Rufiange M, Dumont M, Lachapelle P. Correlating retinal function with melatonin secretion in subjects with an early or late circadian phase. Investigative ophthalmology \& visual science. 2002; 43:2491-2499. [PubMed: 12091455]

72. Lack L, Wright $\mathrm{H}$. The effect of evening bright light in delaying the circadian rhythms and lengthening the sleep of early morning awakening insomniacs. Sleep. 1993; 16:436-443. [PubMed: 8378685]

73. Campbell SS, Dawson D, Anderson MW. Alleviation of sleep maintenance insomnia with timed exposure to bright light. Journal of the American Geriatrics Society. 1993; 41:829-836. [PubMed: 8340561]

74. Sack RL, Lewy AJ, Blood ML, Keith LD, Nakagawa H. Circadian rhythm abnormalities in totally blind people: incidence and clinical significance. The Journal of clinical endocrinology and metabolism. 1992; 75:127-134. [PubMed: 1619000]

75. Hayakawa T, Uchiyama M, Kamei Y, et al. Clinical analyses of sighted patients with non-24-hour sleep-wake syndrome: a study of 57 consecutively diagnosed cases. Sleep. 2005; 28:945-952. [PubMed: 16218077] 
76. Boivin DB, James FO, Santo JB, Caliyurt O, Chalk C. Non-24-hour sleep-wake syndrome following a car accident. Neurology. 2003; 60:1841-1843. [PubMed: 12796546]

77. Ayalon L, Borodkin K, Dishon L, Kanety H, Dagan Y. Circadian rhythm sleep disorders following mild traumatic brain injury. Neurology. 2007; 68:1136-1140. [PubMed: 17404196]

78. Uchiyama M, Shibui K, Hayakawa T, et al. Larger phase angle between sleep propensity and melatonin rhythms in sighted humans with non-24-hour sleep-wake syndrome. Sleep. 2002; 25:83-88. [PubMed: 11833864]

79. Reid KJ, Zee PC. Circadian rhythm disorders. Seminars in neurology. 2009; 29:393-405. [PubMed: 19742414]

80. Oren DA, Wehr TA. Hypernyctohemeral syndrome after chronotherapy for delayed sleep phase syndrome. The New England journal of medicine. 1992; 327:1762. [PubMed: 1435929]

81. Sack RL, Brandes RW, Kendall AR, Lewy AJ. Entrainment of free-running circadian rhythms by melatonin in blind people. The New England journal of medicine. 2000; 343:1070-1077. [PubMed: 11027741]

82. Lewy AJ, Bauer VK, Hasler BP, Kendall AR, Pires ML, Sack RL. Capturing the circadian rhythms of free-running blind people with $0.5 \mathrm{mg}$ melatonin. Brain research. 2001; 918:96-100. [PubMed: 11684046]

83. Hack LM, Lockley SW, Arendt J, Skene DJ. The effects of low-dose 0.5 -mg melatonin on the freerunning circadian rhythms of blind subjects. Journal of biological rhythms. 2003; 18:420-429. [PubMed: 14582858]

84. Kamgar-Parsi B, Wehr TA, Gillin JC. Successful treatment of human non-24-hour sleep-wake syndrome. Sleep. 1983; 6:257-264. [PubMed: 6622881]

85. Hoogendijk WJ, van Someren EJ, Mirmiran M, et al. Circadian rhythm-related behavioral disturbances and structural hypothalamic changes in Alzheimer's disease. International psychogeriatrics / IPA. 1996; 8(3):245-252. discussion 269-272. [PubMed: 9154571]

86. Witting W, Kwa IH, Eikelenboom P, Mirmiran M, Swaab DF. Alterations in the circadian restactivity rhythm in aging and Alzheimer's disease. Biological psychiatry. 1990; 27:563-572. [PubMed: 2322616]

87. Pollak CP, Stokes PE. Circadian rest-activity rhythms in demented and nondemented older community residents and their caregivers. Journal of the American Geriatrics Society. 1997; 45:446-452. [PubMed: 9100713]

88. Palm L, Blennow G, Wetterberg L. Correction of non-24-hour sleep/wake cycle by melatonin in a blind retarded boy. Annals of neurology. 1991; 29:336-339. [PubMed: 2042950]

89. Wagner DR. Disorders of the circadian sleep-wake cycle. Neurologic clinics. 1996; 14:651-670. [PubMed: 8871981]

90. Zee PC, Vitiello MV. Circadian Rhythm Sleep Disorder: Irregular Sleep Wake Rhythm Type. Sleep medicine clinics. 2009; 4:213-218. [PubMed: 20160950]

91. Mishima K, Okawa M, Hishikawa Y, Hozumi S, Hori H, Takahashi K. Morning bright light therapy for sleep and behavior disorders in elderly patients with dementia. Acta psychiatrica Scandinavica. 1994; 89:1-7. [PubMed: 8140901]

92. Dowling GA, Burr RL, Van Someren EJ, et al. Melatonin and bright-light treatment for restactivity disruption in institutionalized patients with Alzheimer's disease. Journal of the American Geriatrics Society. 2008; 56:239-246. [PubMed: 18070004]

93. McCurry SM, Gibbons LE, Logsdon RG, Vitiello MV, Teri L. Nighttime insomnia treatment and education for Alzheimer's disease: a randomized, controlled trial. Journal of the American Geriatrics Society. 2005; 53:793-802. [PubMed: 15877554]

94. Martin JL, Marler MR, Harker JO, Josephson KR, Alessi CA. A multicomponent nonpharmacological intervention improves activity rhythms among nursing home residents with disrupted sleep/wake patterns. The journals of gerontology Series A, Biological sciences and medical sciences. 2007; 62:67-72.

95. Riemersma-van der Lek RF, Swaab DF, Twisk J, Hol EM, Hoogendijk WJ, Van Someren EJ. Effect of bright light and melatonin on cognitive and noncognitive function in elderly residents of group care facilities: a randomized controlled trial. JAMA: the journal of the American Medical Association. 2008; 299:2642-2655. [PubMed: 18544724] 
96. Gehrman PR, Connor DJ, Martin JL, Shochat T, Corey-Bloom J, Ancoli-Israel S. Melatonin fails to improve sleep or agitation in double-blind randomized placebo-controlled trial of institutionalized patients with Alzheimer disease. The American journal of geriatric psychiatry: official journal of the American Association for Geriatric Psychiatry. 2009; 17:166-169. [PubMed: 19155748]

97. Pillar G, Shahar E, Peled N, Ravid S, Lavie P, Etzioni A. Melatonin improves sleep-wake patterns in psychomotor retarded children. Pediatric neurology. 2000; 23:225-228. [PubMed: 11033284]

98. Drake CL, Roehrs T, Richardson G, Walsh JK, Roth T. Shift work sleep disorder: prevalence and consequences beyond that of symptomatic day workers. Sleep. 2004; 27:1453-1462. [PubMed: 15683134]

99. Harma MI, Hakola T, Akerstedt T, Laitinen JT. Age and adjustment to night work. Occupational and environmental medicine. 1994; 51:568-573. [PubMed: 7951784]

100. Folkard S, Monk TH, Lobban MC. Short and long-term adjustment of circadian rhythms in 'permanent' night nurses. Ergonomics. 1978; 21:785-799. [PubMed: 729546]

101. Knauth P, Landau K, Droge C, Schwitteck M, Widynski M, Rutenfranz J. Duration of sleep depending on the type of shift work. International archives of occupational and environmental health. 1980; 46:167-177. [PubMed: 7399725]

102. Akerstedt T. Work hours, sleepiness and the underlying mechanisms. Journal of sleep research. 1995; 4:15-22. [PubMed: 10607206]

103. Morgenthaler T, Alessi C, Friedman L, et al. Practice parameters for the use of actigraphy in the assessment of sleep and sleep disorders: an update for 2007. Sleep. 2007; 30:519-529. [PubMed: 17520797]

104. Hart CL, Ward AS, Haney M, Foltin RW. Zolpidem-related effects on performance and mood during simulated night-shift work. Experimental and clinical psychopharmacology. 2003; 11:259-268. [PubMed: 14599259]

105. Moon CA, Hindmarch I, Holland RL. The effect of zopiclone $7.5 \mathrm{mg}$ on the sleep, mood and performance of shift workers. International clinical psychopharmacology. 1990; 5(Suppl 2):79_ 83. [PubMed: 2201732]

106. Hart CL, Haney M, Nasser J, Foltin RW. Combined effects of methamphetamine and zolpidem on performance and mood during simulated night shift work. Pharmacology, biochemistry, and behavior. 2005; 81:559-568.

107. Van Camp RO. Zolpidem in fatigue management for surge operations of remotely piloted aircraft. Aviation, space, and environmental medicine. 2009; 80:553-555.

108. Monchesky TC, Billings BJ, Phillips R, Bourgouin J. Zopiclone in insomniac shiftworkers. Evaluation of its hypnotic properties and its effects on mood and work performance. International archives of occupational and environmental health. 1989; 61:255-259. [PubMed: 2656527]

109. Walsh JK, Schweitzer PK, Anch AM, Muehlbach MJ, Jenkins NA, Dickins QS. Sleepiness/ alertness on a simulated night shift following sleep at home with triazolam. Sleep. 1991; 14:140 146. [PubMed: 1866527]

110. Dawson D, Campbell SS. Timed exposure to bright light improves sleep and alertness during simulated night shifts. Sleep. 1991; 14:511-516. [PubMed: 1798884]

111. Crowley SJ, Lee C, Tseng CY, Fogg LF, Eastman CI. Combinations of bright light, scheduled dark, sunglasses, and melatonin to facilitate circadian entrainment to night shift work. Journal of biological rhythms. 2003; 18:513-523. [PubMed: 14667152]

112. Boivin DB, James FO. Circadian adaptation to night-shift work by judicious light and darkness exposure. Journal of biological rhythms. 2002; 17:556-567. [PubMed: 12465889]

113. Eastman CI, Stewart KT, Mahoney MP, Liu L, Fogg LF. Dark goggles and bright light improve circadian rhythm adaptation to night-shift work. Sleep. 1994; 17:535-543. [PubMed: 7809567]

114. Campbell SS, Dijk DJ, Boulos Z, Eastman CI, Lewy AJ, Terman M. Light treatment for sleep disorders: consensus report. III. Alerting and activating effects. Alerting and activating effects Journal of biological rhythms. 1995; 10:129-132.

115. Cajochen C. Alerting effects of light. Sleep medicine reviews. 2007; 11:453-464. [PubMed: 17936041] 
116. Bjorvatn B, Stangenes K, Oyane N, et al. Randomized placebo-controlled field study of the effects of bright light and melatonin in adaptation to night work. Scandinavian journal of work, environment \& health. 2007; 33:204-214.

117. Czeisler CA, Walsh JK, Roth T, et al. Modafinil for excessive sleepiness associated with shiftwork sleep disorder. The New England journal of medicine. 2005; 353:476-486. [PubMed: 16079371]

118. Muehlbach MJ, Walsh JK. The effects of caffeine on simulated night-shift work and subsequent daytime sleep. Sleep. 1995; 18:22-29. [PubMed: 7761739]

119. Babkoff H, French J, Whitmore J, Sutherlin R. Single-dose bright light and/or caffeine effect on nocturnal performance. Aviation, space, and environmental medicine. 2002; 73:341-350.

120. Czeisler CA, Walsh JK, Wesnes KA, Arora S, Roth T. Armodafinil for treatment of excessive sleepiness associated with shift work disorder: a randomized controlled study. Mayo Clinic proceedings Mayo Clinic. 2009; 84:958-972. [PubMed: 19880686]

121. Boulos Z, Campbell SS, Lewy AJ, Terman M, Dijk DJ, Eastman CI. Light treatment for sleep disorders: consensus report. VII. Jet lag. Journal of biological rhythms. 1995; 10:167-176. [PubMed: 7632990]

122. Burgess HJ, Crowley SJ, Gazda CJ, Fogg LF, Eastman CI. Preflight adjustment to eastward travel: 3 days of advancing sleep with and without morning bright light. Journal of biological rhythms. 2003; 18:318-328. [PubMed: 12932084]

123. Eastman CI, Gazda CJ, Burgess HJ, Crowley SJ, Fogg LF. Advancing circadian rhythms before eastward flight: a strategy to prevent or reduce jet lag. Sleep. 2005; 28:33-44. [PubMed: 15700719]

124. Beaumont M, Batejat D, Pierard C, et al. Caffeine or melatonin effects on sleep and sleepiness after rapid eastward transmeridian travel. J Appl Physiol. 2004; 96:50-58. [PubMed: 12959951]

125. Srinivasan V, Spence DW, Pandi-Perumal SR, Trakht I, Cardinali DP. Jet lag: therapeutic use of melatonin and possible application of melatonin analogs. Travel medicine and infectious disease. 2008; 6:17-28. [PubMed: 18342269]

126. Zee PC, Wang-Weigand S, Wright KP Jr, Peng X, Roth T. Effects of ramelteon on insomnia symptoms induced by rapid, eastward travel. Sleep medicine. 2010; 11:525-533. [PubMed: 20483660]

127. Rosenberg RP, Bogan RK, Tiller JM, et al. A phase 3, double-blind, randomized, placebocontrolled study of armodafinil for excessive sleepiness associated with jet lag disorder. Mayo Clinic proceedings Mayo Clinic. 2010; 85:630-638. [PubMed: 20530317]

128. Jamieson AO, Zammit GK, Rosenberg RS, Davis JR, Walsh JK. Zolpidem reduces the sleep disturbance of jet lag. Sleep medicine. 2001; 2:423-430. [PubMed: 14592392]

129. Khalsa SB, Jewett ME, Cajochen C, Czeisler CA. A phase response curve to single bright light pulses in human subjects. The Journal of physiology. 2003; 549:945-952. [PubMed: 12717008] 


\section{Key Points Box}

1. The endogenous human circadian rhythm is genetically determined. This near 24 hour oscillation is generated by a central clock located in the suprachiasmatic nucleus of the hypothalamus, and regulates the timing of most physiological and behavioral cycles, including sleep and wake.

2. Light is the strongest synchronizing agent for the circadian clock. However, non-photic signals, such as melatonin and both social and physical activity can also timing of circadian rhythms.

3. The ability of synchronizing agents to shift the timing of circadian rhythms is dependent on the time, intensity and duration of exposure.

4. Circadian rhythm sleep disorders are characterized by a persistent or recurrent pattern of sleep disturbance (difficulty falling asleep or staying asleep and excessive sleepiness) due to alterations of the circadian timekeeping system and/ or misalignment of the endogenous circadian rhythm and the external environment. These include delayed sleep phase disorder, advanced sleep phase disorder, irregular sleep wake rhythm, free-running disorder, shift work disorder and jet lag disorder.

5. Effective treatment of CRSD requires a multimodal approach using the principles of sleep hygiene, timed exposure to light and melatonin, and avoidance of bright light at inappropriate times. 


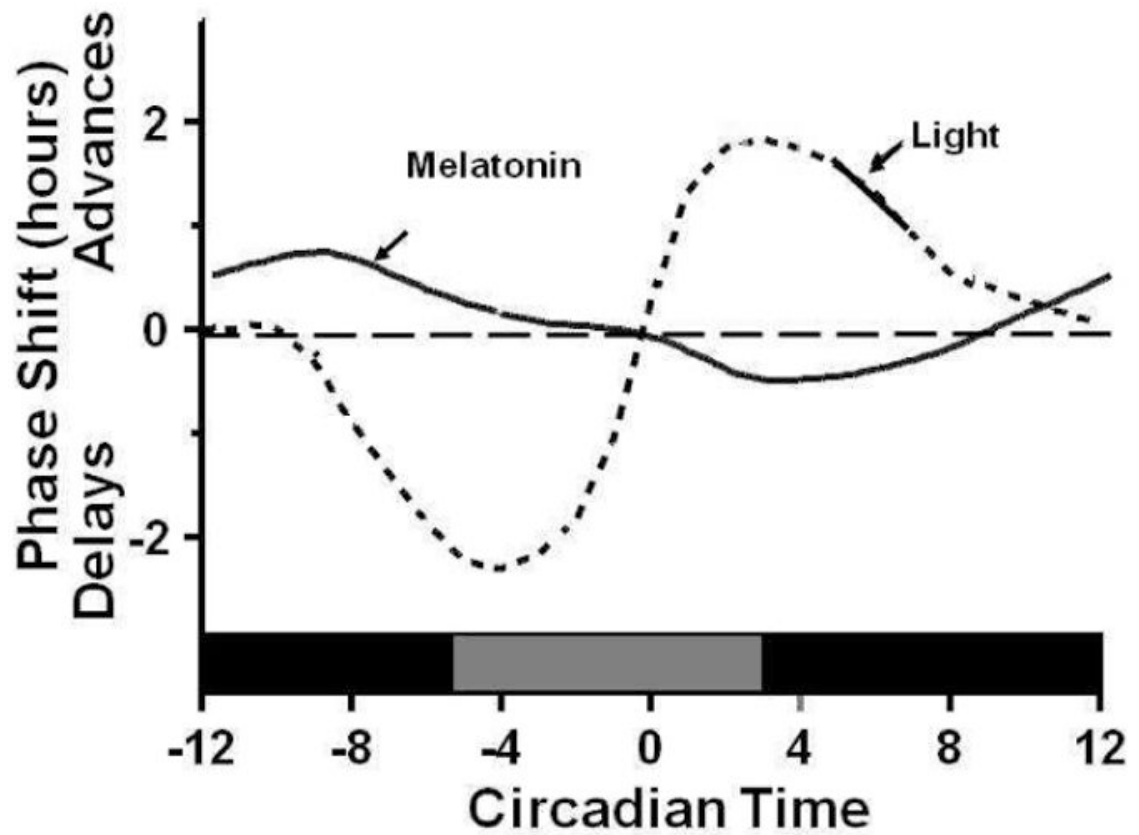

Figure 1. Schematic representation of the phase response curves to light and melatonin Circadian time point 0 is the timing of the nadir of the circadian core temperature rhythm. Light exposure prior to the temperature nadir results in a delay of circadian rhythms, whereas light exposure after the temperature nadir causes phase advances. Note that there is a dead zone in the middle of the day where bright light exposure has no effect on the timing of circadian rhythms. In contrast, melatonin administered in the beginning of the night advances the circadian rhythm, while melatonin in the morning delays the circadian rhythm. The figure is derived from data presented by Lewy et $\mathrm{al}^{32}$ and Khalsa et al ${ }^{129}$. The figure is reprinted with permission (from Zee PC and Manthena P. The brain's master circadian clock: implications and opportunities for therapy of sleep disorders; Sleep Medicine Review 2007 Feb;11(1):59-70). 


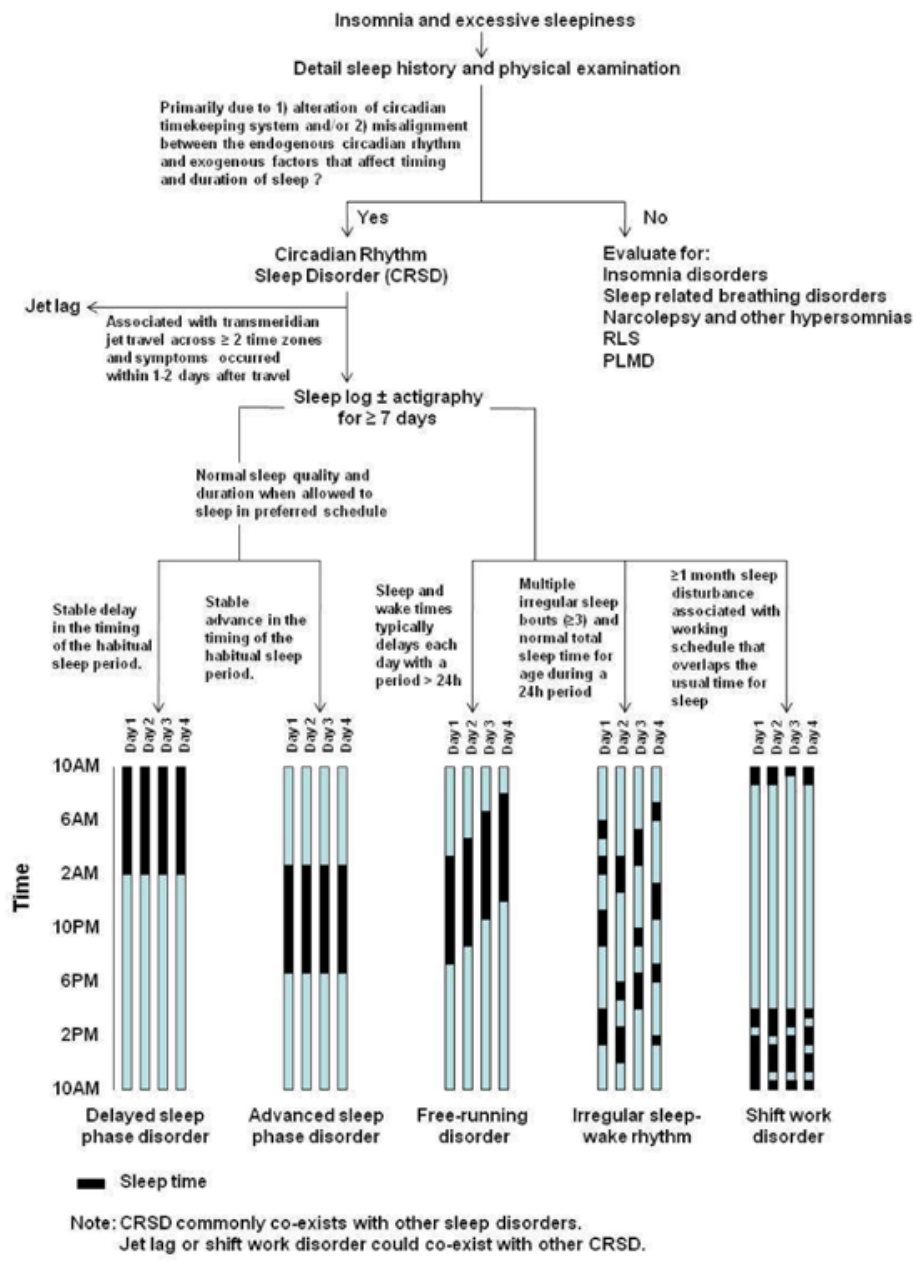

Figure 2. Clinical approach to the diagnosis of circadian rhythm sleep disorders (CRSD) A history of sleep and wake disturbance due to alteration of circadian timing and function is the mainstay of the clinical diagnosis. It is important to consider other sleep disorders and mood disorders in the differential diagnosis of most CRSDs. The pattern of sleep and wake disturbance differs among the various types of CRSDs as illustrated in this figure. 
A

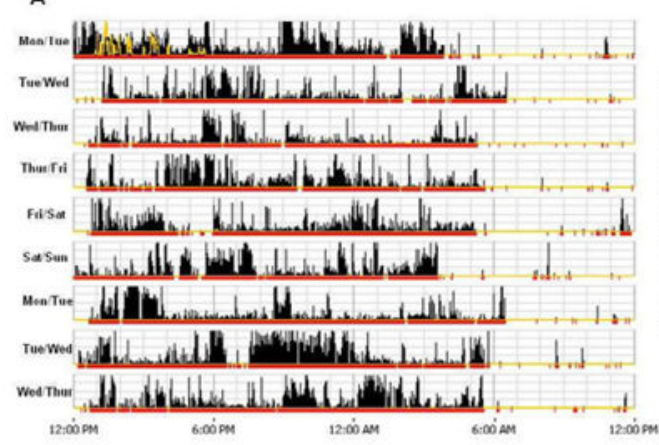

B

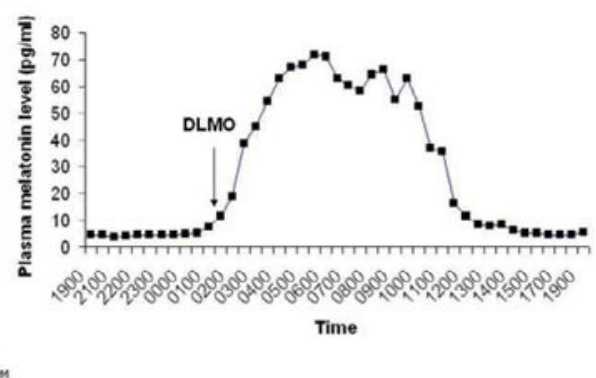

Figure 3. Actogram of a patient with DSPD

Panel A shows an actogram derived from actigraphy data obtained over 9 days in a patient with severe DSPD. The yellow lines depict light exposure. The high amplitude dense bars are representative of wakefulness and no to low activity time is representative of sleep. Note that average sleep onset is 5-6 am and wake time from noon to $1 \mathrm{pm}$. Note the stable delay of the sleep-wake rhythm in relation to the conventional sleep time and wake-up time. Panel B shows the 24-hour plasma melatonin level rhythm of this patient. The dim light melatonin onset (DLMO) was defined as an absolute threshold at $10 \mathrm{pg} / \mathrm{mL}$. The DLMO of this patient is delayed at 1:23am (which is approximately 5 hours later than would be expected in nondelayed persons). 
A

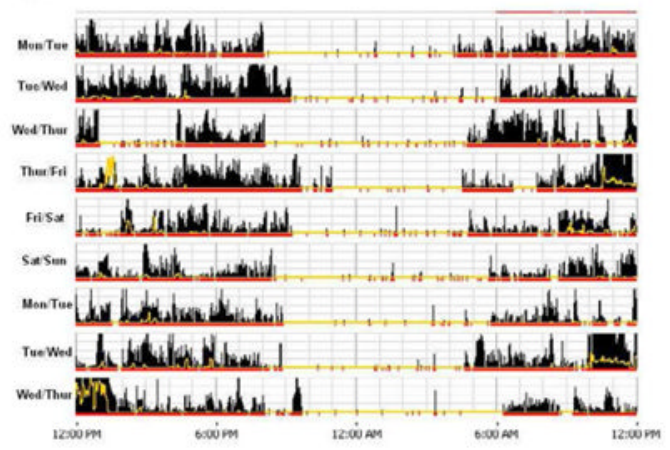

B

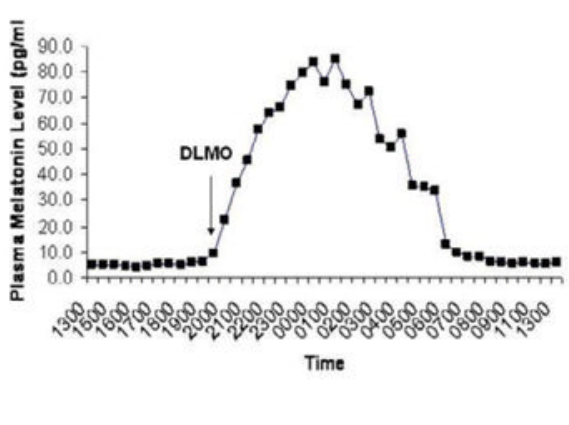

Figure 4. Actogram of a patient with ASPD

Panel A shows an actogram derived from actigraphy data obtained over 9 days in a patient with severe ASPD. The yellow lines depict light exposure. The high amplitude dense bars are representative of wakefulness and no to low activity time is representative of sleep. Note that average sleep onset is 8:00 to 9:00 pm, and wake time from 4:00 to 5:00 am. Note the stable advance of the sleep-wake rhythm in relation to the conventional sleep time and wake-up time. Panel B shows the 24-hour plasma melatonin level rhythm of this patient. The dim light melatonin onset (DLMO) was defined as an absolute threshold at $10 \mathrm{pg} / \mathrm{mL}$. The DLMO of this patient is advanced at $7.30 \mathrm{pm}$ (which is approximately 2-3 hours earlier than would be expected in non-advanced persons). 


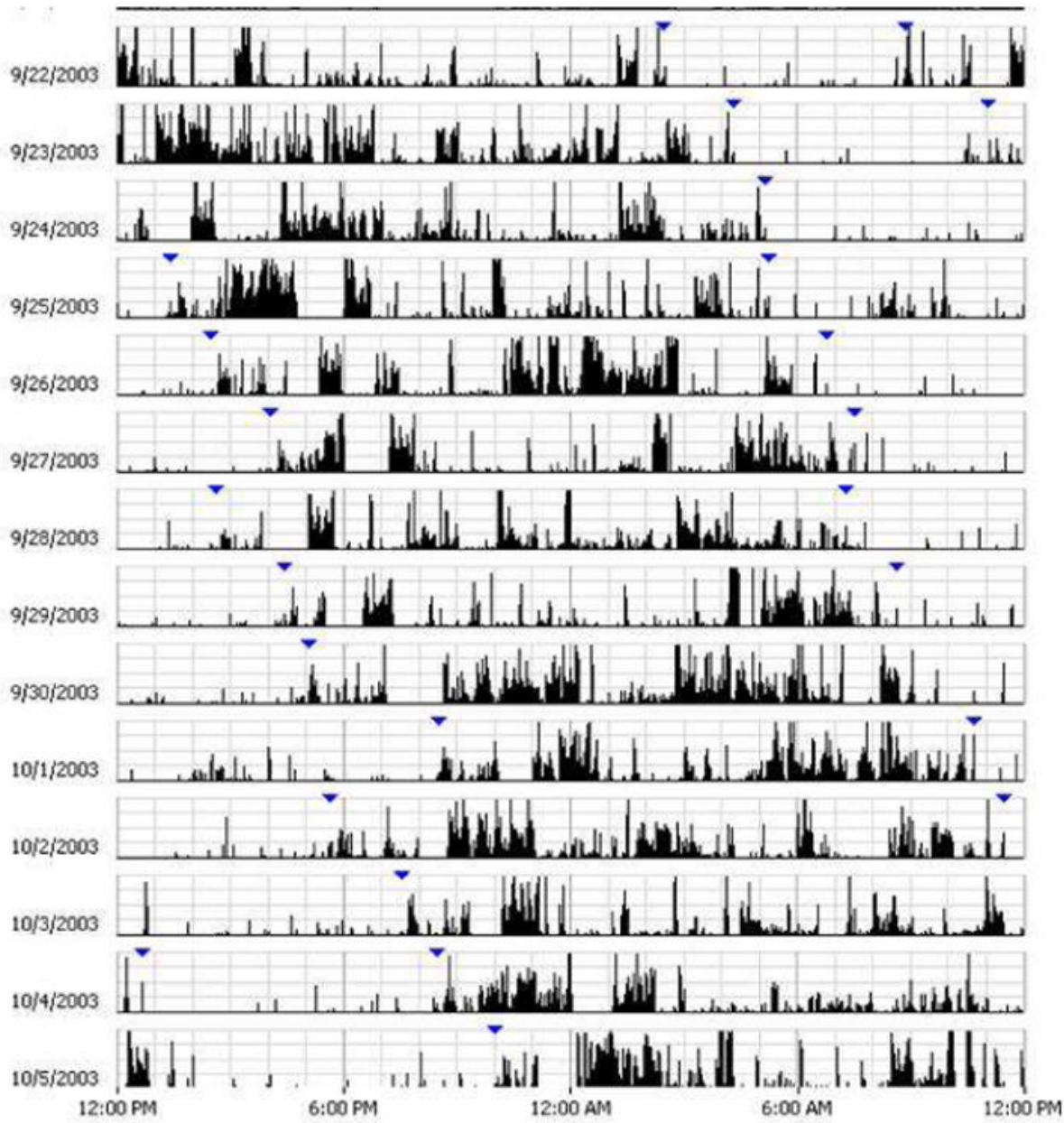

Figure 5. Actogram of a patient with non-24 hour sleep wake disorder (N24HSWD)

Panel A shows an actogram derived from actigraphy data obtained over 14 days in a sighted patient with N24HSWD. The high amplitude dense bars are representative of wakefulness and no to low activity time is representative of sleep. Note the daily drift to later times of the sleep-wake pattern with a period that is slightly longer than 24 hours. 


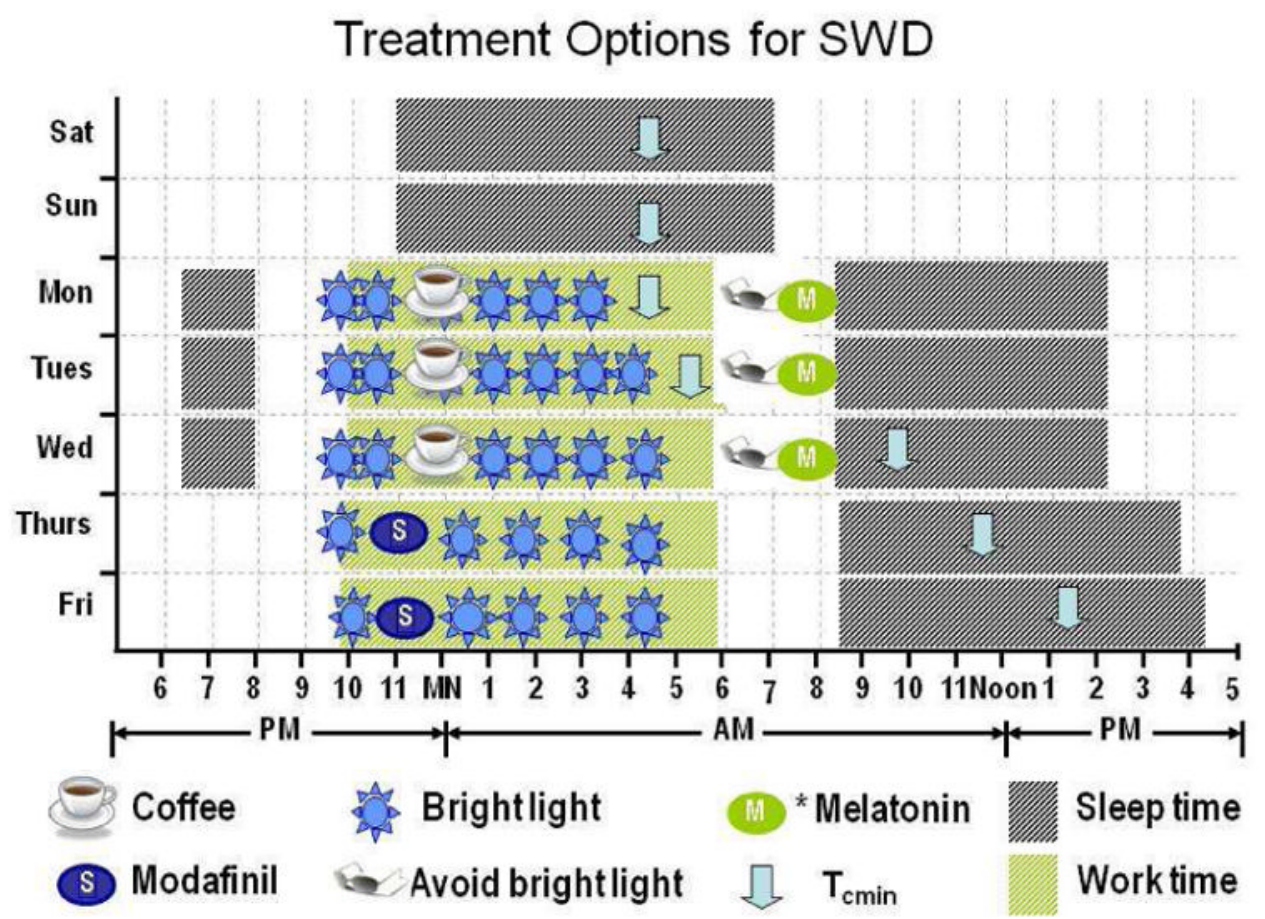

${ }^{*}$ Non-FDA approved use

Figure 6. Treatment Options for the Management of Shift Work Disorder (SWD)

This example illustrates the timing of light exposure and the use of pharmacologic agents, either alone or in combination for the management of SWD. The habitual pre-shift sleep time of this 42 year old male is $11 \mathrm{pm}-7 \mathrm{am}$. The new work shift requires that he work from $10 \mathrm{pm}$ to $6 \mathrm{am}$ for 4-5 days per week. Circadian alignment can be achieved by manipulating light and dark exposure. In order to delay his circadian rhythm, bright light exposure (continuous or intermittent) should start early in the shift and stop about 1-2 hours before the shift, and wear sunglasses to avoid advancing circadian rhythms in the morning. If needed, melatonin taken before bedtime may help improve sleep quality. To address the issue of excessive sleepiness, scheduled 1-2 hour nap prior to the shift work, if possible a short 30 minute nap in the middle of the shift, and/or caffeine can help decrease sleepiness at work. If sleepiness persists, modafinil $200 \mathrm{mg}$ and armodafinil $150 \mathrm{mg}$ have been shown to improve alertness during work and is approved by the FDA for the treatment of excessive sleepiness in patients with SWD. 


\section{A}
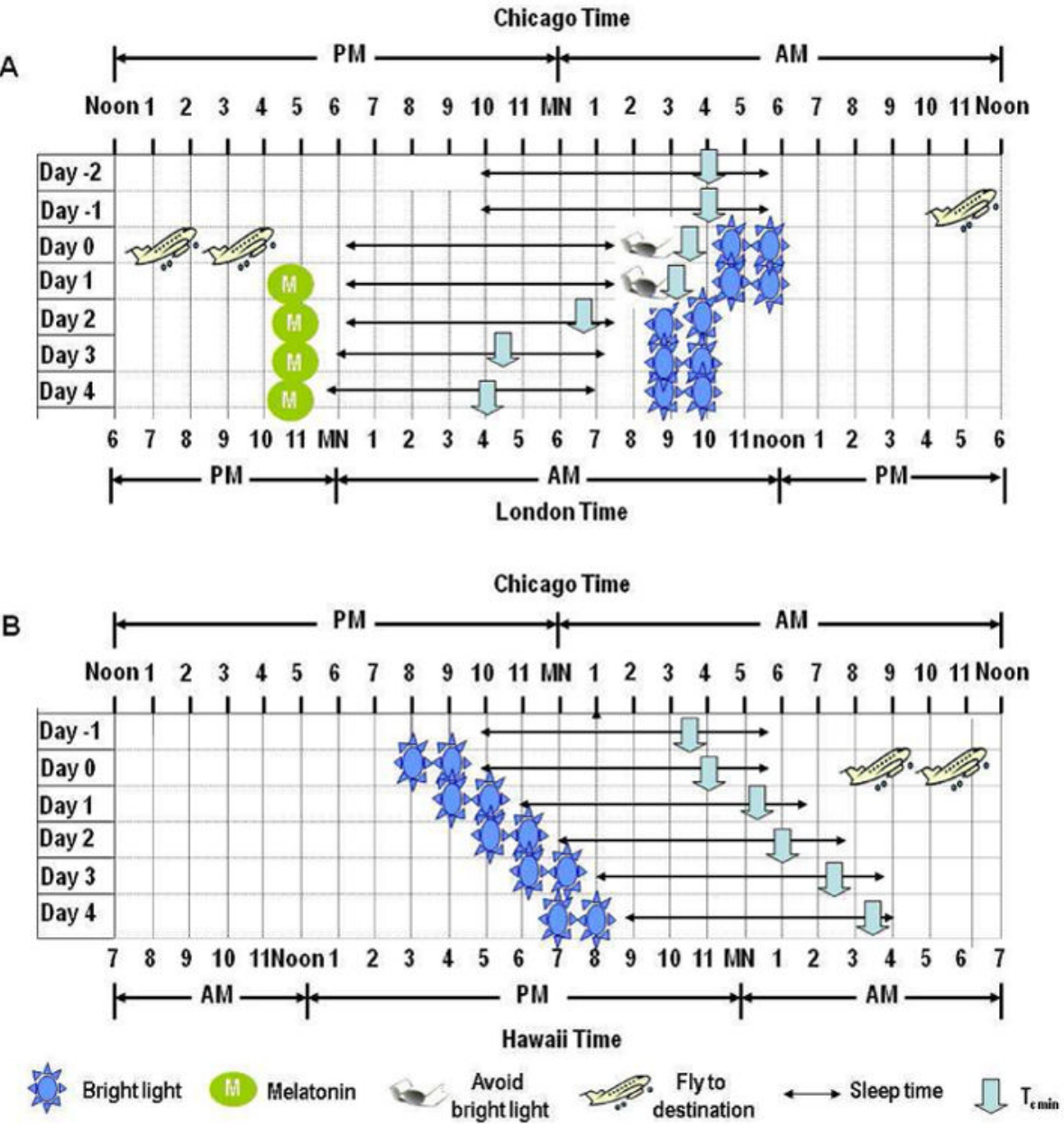

Figure 7. Strategies to accelerate circadian adaption to jet lag

Panel A illustrates an example of a treatment strategy for jet lag associated with an eastward flight over six time zones (from Chicago to London). Adjustment requires an equal number of hours of phase advance. Upon arrival, the traveler should avoid bright light in the early morning hours (before $9 \mathrm{am}$ ) for the first 2 days so that light does not fall before nadir of the minimum of the core temperature (which will induce a phase delay), and exposure to bright light after $9 \mathrm{am}$ in the morning to induce phase advances. In addition, melatonin $1-5 \mathrm{mg}$ taken at 1800 local time on the departure day and at local bedtime (2200-2300) on arrival for 4 days has shown to be effective ${ }^{124}$. Panel B illustrates the treatment strategy for jet lag associated with a westward flight over five time zones (from Chicago to Hawaii). The subject should be exposed as much as light as possible in the late afternoon and early evening to at the destination, which will result in the required phase delay. 
Table 1

Overview of clinical features and treatment of circadian rhythm sleep disorders (CRSD) *

\begin{tabular}{|l|l|l|}
\hline Disorder & Clinical Features & Treatment \\
\hline $\begin{array}{l}\text { Delayed leep phase } \\
\text { disorder (DSPD) }\end{array}$ & $\begin{array}{l}\text { Stable delay of the major sleep period, resulting in } \\
\text { difficulty falling asleep at night and difficulty waking up in } \\
\text { the monring }\end{array}$ & $\begin{array}{l}\text { Bright ight therapy 2,000-2:500 lux for 2 hours at or } \\
\text { 2-3hours prior to habitual rise time } \\
0.5 \mathrm{mg}-3 \mathrm{mg} \text { melatonin 5-7h prior to steep time }\end{array}$ \\
\hline $\begin{array}{l}\text { Advanced sleep phase } \\
\text { disorder (ASPD) }\end{array}$ & $\begin{array}{l}\text { Stable advance of the major sleep period, resulting in } \\
\text { difficulty staying awake in the evening and difficulty } \\
\text { maintaining asleep in the morning }\end{array}$ & $\begin{array}{l}\text { Bright light therapy 2,000-2,500 iux for 2h in } \\
\text { evening (around 7-9pm) }\end{array}$ \\
\hline $\begin{array}{l}\text { Non-24 Hour Sleep } \\
\text { Wake Disorder } \\
\text { (N24HSWD) }\end{array}$ & $\begin{array}{l}\text { Chronic and steady 1 to 2 hours daily delay of sleep and } \\
\text { wake schedule resutting in insomnia, difficulty waking up } \\
\text { in the morning and excessive daytime sleepiness }\end{array}$ & $\begin{array}{l}\text { Blind - 0 5mg melatonin 1h before preferred } \\
\text { bedtime. Sighted - morning bright light therapy at } \\
\text { rise time and/or night melatonin administration }\end{array}$ \\
\hline $\begin{array}{l}\text { Irregular Sleep-Wake } \\
\text { Rhythm (ISWR) }\end{array}$ & $\begin{array}{l}\text { Absence of a clearly discernable sleep-wake circadian } \\
\text { rhythm resulting in insomnia and/or excessive daytime } \\
\text { sleepiness }\end{array}$ & $\begin{array}{l}\text { Increase daytime light exposure and social activity } \\
\text { Minimize nighttime light and noise exposure } \\
\text { Evening melatonin administration combined with } \\
\text { daytime light exposure }\end{array}$ \\
\hline
\end{tabular}

Sleep hygiene is an important component to treat CRSD 